COSTING:Journal of Economic, Business and Accounting

Volume 4 Nomor 1, Desember 2020

e-ISSN : 2597-5234

\title{
PENERAPAN BIAYA STANDAR DALAM PENGENDALIAN BIAYA PRODUKSI
}

\author{
IMPLEMENTATION OF STANDARD COSTS \\ IN CONTROL OF PRODUCTION COSTS
}

\author{
Dewi Anggraini $^{1}$, Yuli Nurhayati ${ }^{2}$ \\ Universitas Bina Insan Lubuklinggau ${ }^{1,2}$ \\ Dewianggraini2020@gmail.com ${ }^{1}$
}

\begin{abstract}
This study aims to determine the control of production costs by applying standard costs in the Kerupuk Khas Malalo Industry of Lubuklinggau City. This research is a qualitative research. The data sources used are primary data sources and secondary data sources. The data collection techniques used were interviews, observation and documentation. The results showed that the Jangek Khas Malalo Crackers Industry in Lubuklinggau City experienced an unfavorable difference in purchasing raw materials, controlling labor costs had not been effective because of the increase in wage rates and the addition of one employee as well as controlling factory overhead costs as well. has not been effective because it does not perform calculations in accordance with the actual calculation. In conclusion, the Jangek Khas Malalo cracker industry in Lubuklinggau City has not controlled production costs properly in production activities and has experienced an unfavorable difference due to the increase in costs incurred in production activities.
\end{abstract}

Keywords: Production Costs, Standard Costs, Control

\begin{abstract}
ABSTRAK
Penelitian ini bertujuan untuk mengetahui pengendalian biaya produksi dengan menerapkan biaya standar di Industri Kerupuk Jangek Khas Malalo Kota Lubuklinggau. Penelitian ini adalah penelitian kualitatif. Sumber data yang digunakan adalah sumber data primer dan sumber data sekunder. Teknik pengumpulan data yang digunakan adalah wawancara, observasi dan dokumentasi. Hasil penelitian menunjukkan bahwa Industri Kerupuk Jangek Khas Malalo Kota Lubuklinggau ini mengalami selisih yang tidak menguntungkan (unfavorable) dalam pembelian bahan baku, pengendalian biaya tenaga kerja belum berjalan secara efektif karena kenaikan tarif upah dan adanya penambahan karyawan sebanyak 1 orang serta pengendalian biaya overhead pabrik juga belum berjalan efektif karena tidak melakukan perhitungan sesuai dengan perhitungan yang sesungguhnya. Simpulan, Industri Kerupuk Jangek Khas Malalo Kota Lubuklinggau belum mengendalikan biaya produksi dengan baik dalam kegiatan produksi dan mengalami selisih yang tidak menguntungkan karena dipengaruhi oleh kenaikan biaya yang dikeluarkan dalam kegiatan produksi.
\end{abstract}

Kata Kunci: Biaya Produksi, Biaya Standar, Pengendalian 


\section{PENDAHULUAN}

Seiring dengan perkembangan dunia usaha, pertumbuhan ekonomi, kemajuan teknologi yang pesat dan faktor lainnya yang mempunyai pengaruh terhadap kegiatan perusahaan menjadikan akuntansi saat ini mempunyai beberapa bidang khusus. Bidang- bidang akuntansi tersebut diantaranya adalah akuntansi keuangan, akuntansi manajemen, akuntansi biaya, pengauditan dan perpajakan.

Bidang akuntansi yang berperan dalam dalam mencatat biaya berdasarkan informasi yang relevan dan akurat adalah akuntansi biaya. Selain itu akuntansi biaya juga berfungsi untuk memotivasi manajemen dan karyawan dalam melakukan pengurangan biaya (cost reduction) agar perusahaan mempunyai keunggulan dalam segi biaya (Kurniawan, 2012).

Perencanaan biaya standar yang terperinci dengan baik sangat penting dalam pengambilan keputusan. Menurut Mulyadi (2014) biaya standar adalah biaya yang ditentukan di muka dan merupakan jumlah biaya yang seharusnya dikeluarkan untuk membuat satu satuan produk atau untuk membiayai kegiatan tertentu, di bawah asumsi kondisi ekonomi, efisien dan faktor-faktor tertentu lainnya. Biaya standar sangat penting dalam kegiatan produksi karena berperan dalam mengendalikan biaya produksi dalam produktifitas yang meliputi biaya bahan baku standar, biaya tenaga kerja standar dan biaya overhead pabrik standar terhadap biaya produksi.

Usaha Mikro Kecil dan

Menengah (UMKM) adalah usaha produktif yang dimiliki perseorangan maupun badan usaha yang telah memenuhi kriteria usaha mikro. Berdasarkan undang-undang No.20 tahun 2008 tentang UMKM yang disebut sebagai usaha kecil adalah entitias yang memiliki kekayaan bersih lebih dari Rp50.000.000,- sampai dengan Rp500.000.000,00 memiliki hasil penjualan tahunan lebih dari Rp300.000.000,00 sampai Rp2.500.000.000,00. Oleh karena itu, dapat dipastikan bahwa Industri Kerupuk Jangek Khas Malalo Lubuklinggau adalah salah satu bagian dari UMKM yang sedang berkembang. Usaha ini yang berdiri pada tahun 2009 yang dipimpin oleh Bapak Ma'ruf dengan modal awal yaitu sebesar Rp155.000.000,00. Hingga saat ini usaha kerupuk jangek sudah berkembang dalam pemasarannya. Dalam kegiatan produksi tentunya memerlukan perhitungan biaya bahan baku, biaya tenaga kerja dan biaya overhead pabrik.

Dalam melakukan perhitungan biaya tersebut tentu harus disertakan dengan perhitungan di awal kegiatan produksi yang disebut biaya standar dan dalam kegiatan produksi akan dilakukan kembali perhitungan biaya akrual. Dalam kedua perhitungan tersebut tentu memiliki selisih, dimana selisih tersebut membutuhkan analisis varians agar dapat mengetahui jumlah selisih. Dengan adanya penerapan biaya standar, maka dapat dilakukan pengendalian biaya produksi. Hal ini sesuai dengan pernyataan Salmon \& Runtu (2016) bahwa penerapan sistem biaya standar berguna untuk memperbaiki perencanaan dan pengendalian serta untuk memfasilitasi perhitungan biaya produk. Namun kenyataannya, Kerupuk Jangek Khas Malalo tidak melakukan perhitungan biaya standar dalam kegiatan produksinya baik untuk mengukur seberapa besar selisih biaya dalam setiap produksinya selama 1 bulan produksi maupun 1 tahun produksi, melainkan hanya catatan biaya produksi yang telah digunakan. 
Permasalahan tersebutlah yang mendasari ketertarikan peneliti untuk melakukan analisis tentang sistem pengendalian biaya produksi dengan menerapkan biaya standar di Industri Kerupuk Jangek Khas Malalo Kota Lubuklinggau.

\section{METODE PENELITIAN}

Penelitian ini dilakukan di Industri Kerupuk Jangek Khas Malalo dengan menggunakan data selama 3 tahun, mulai dari tahun 2016-2018 dengan menggunakan metode penelitian kualitatif. Sumber data yang digunakan yaitu data primer dan sekunder. Data primer merupakan data yang dikumpulkan dengan teknik observasi dan wawancara, sedangkan data sekunder diperoleh dengan teknik dokumentasi yaitu berupa data historis perusahaan yang telah diarsipkan.

\section{HASIL DAN PEMBAHASAN}

Industri Kerupuk Jangek Khas Malalo Kota Lubuklinggau yang mempunyai aktifitas utama mengelola bahan baku (kulit sapi kering) menjadi kerupuk jangek yang siap dijual dan siap dikonsumsi konsumen. Tujuan Industri Kerupuk Jangek Khas Malalo Kota Lubuklinggau ini untuk meminimalisir biaya produksi dengan memperhitungkan biaya historis produksi yang digunakan sebagai biaya standar dan menghitung biaya akrual sebai biaya sesungguhnya dengan tujuan agar dapat meningkatkan laba yang akan diperoleh di priode selanjutnya.

\section{Penetapan Biaya Standar di Industri Kerupuk Jangek Khas Malalo}

Industri Kerupuk Jangek Khas Malalo belum memperhitungkan dan menerapkan biaya standar karena pihak industri belum mengetahui bagaimana perhitungan biaya standar dan analisis biaya standar, maka dari itu peneliti melakukan perhitungan terlebih dahulu.

\section{Biaya Bahan Baku}

Tabel 1 Selisih Biaya Bahan Baku

\begin{tabular}{ccc}
\hline $\begin{array}{c}\text { Tahun 2016 } \\
(\mathrm{Rp})\end{array}$ & $\begin{array}{c}\text { Tahun 2017 } \\
(\mathrm{Rp})\end{array}$ & $\begin{array}{c}\text { Selisih Biaya } \\
\text { Bahan Baku } \\
(\mathrm{Rp})\end{array}$ \\
\hline 695.612 .000 & 797.382 .000 & 101.770 .000 \\
\hline $\begin{array}{c}\text { Tahun 2017 } \\
(\mathrm{Rp})\end{array}$ & $\begin{array}{c}\text { Tahun 2018 } \\
(\mathrm{Rp})\end{array}$ & $\begin{array}{c}\text { Selisih Biaya } \\
\text { Bahan Baku } \\
(\mathrm{Rp})\end{array}$ \\
\hline 797.382 .000 & 949.344 .000 & 151.962 .000 \\
\hline
\end{tabular}

(Sumber: Data diolah peneliti, 2019)

Tabel 2 Rekapitulasi Selisih Biaya Bahan Baku 2017

\begin{tabular}{cc}
\hline Selisih & Jumlah (Rp) \\
\hline $\begin{array}{c}\text { Selisih Biaya Bahan } \\
\text { Baku }\end{array}$ & 8.574 .000 \\
\hline Selisih Kuantitas & 93.163 .000 \\
Biaya Bahan Baku & \\
\hline Total Selisih Biaya & 101.770 .00 \\
Bahan Baku & \\
\hline (Sumber: Data diolah peneliti, 2019)
\end{tabular}

Tabel 3 Rekapitulasi Selisih Biaya Bahan Baku 2018

\begin{tabular}{cc}
\hline Selisih & Jumlah $(\mathrm{Rp})$ \\
\hline $\begin{array}{c}\text { Selisih Biaya Bahan } \\
\text { Baku }\end{array}$ & 0 \\
\hline Selisih Kuantitas & 151.962 .000 \\
Biaya Bahan Baku & \\
\hline Total Selisih Biaya & 151.962 .000 \\
Bahan Baku & \\
\hline (Sumber: Data diolah peneliti, 2019)
\end{tabular}

Berdasarkan hasil perhitungan analisis selisih biaya bahan baku, maka dapat diketahui bahwa Industri Kerupuk Jangek Malalo tidak mengalami selisih bahan baku baik yang menguntungkan (favorable) atau tidak menguntungkan (unfavorable). Hal ini disebabkan karena tidak adanya kenaikan maupun penurunan harga bahan baku/Kg kulit sapi kering. Kemudian pada hasil perhitungan analisis selisih kuantitas bahan baku, data menunjukkan bahwa 
Industri Kerupuk Jangek Malalo mengalami selisih kuantitas bahan baku tidak menguntungkan (unfavorable) sebesar Rp151.962.000,00. Hal ini disebabkan naiknya kuantitas bahan baku sebesar $1.634 \mathrm{Kg}$ kulit sapi kering yang digunakan dalam kegiatan produksi.

\section{Biaya Tenaga Kerja}

Biaya tenaga kerja adalah biaya yang wajib dikeluarkan untuk membayar gaji dan upah atas kinerja karyawan baik dibayarkan per hari, per minggu maupun perbulan. Industri Kerupuk Jangek Khas Malalo Kota Lubuklinggau melakukan kegiatan produksi dalam 1 bulan sebanyak 24 hari produksi sehingga pengelola harus memperhitungkan biaya yang harus dikeluarkan untuk membayar karyawan.

Tabel 4 Selisih Biaya Tenaga Kerja

\begin{tabular}{ccc}
\hline $\begin{array}{c}\text { Tahun 2016 } \\
(\mathrm{Rp})\end{array}$ & $\begin{array}{c}\text { Tahun 2017 } \\
(\mathrm{Rp})\end{array}$ & $\begin{array}{c}\text { Selisih Biaya } \\
\text { Bahan Baku } \\
(\mathrm{Rp})\end{array}$ \\
\hline 101.376 .000 & 101.376 .000 & 0 \\
\hline $\begin{array}{c}\text { Tahun 2017 } \\
(\mathrm{Rp})\end{array}$ & $\begin{array}{c}\text { Tahun 2018 } \\
(\mathrm{Rp})\end{array}$ & $\begin{array}{c}\text { Selisih Biaya } \\
\text { Bahan Baku } \\
(\mathrm{Rp})\end{array}$ \\
\hline 101.376.000 & 129.600 .000 & 28.224 .000 \\
\hline \multicolumn{2}{l}{ Sumber: Data diolah peneliti, 2019) }
\end{tabular}

Tabel 5 Rekapitulasi Selisih Biaya Tenaga Kerja 2017

\begin{tabular}{cc}
\hline Selisih & Jumlah $(\mathrm{Rp})$ \\
\hline $\begin{array}{c}\text { Selisih Biaya Tenaga } \\
\text { Kerja }\end{array}$ & 0 \\
\hline $\begin{array}{c}\text { Penyimpangan } \\
\text { Efisiensi BTK }\end{array}$ & 0 \\
\hline Total Selisih BTK & 0 \\
\hline
\end{tabular}

(Sumber: Data diolah peneliti, 2019)

Berdasarkan hasil perhitungan analisis selisih biaya tenaga kerja, dapat diketahui bahwa Industri Kerupuk Jangek Malalo tidak mengalami selisih biaya tenaga yang menguntungkan (favorable) maupun tidak menguntungkan (unfavorable). Hal ini disebabkan karena tidak adanya kenaikan tarif upah yang dilakukan pihak Industri Kerupuk Jangek Malalo dalam menggaji karyawan. Selain itu hasil perhitungan analisis selisih penyimpangan biaya tenaga kerja juga menunjukkan bahwa Industri Kerupuk Jangek Malalo tidak mengalami selisih biaya tenaga yang menguntungkan maupun tidak menguntungkan. Hal ini disebabkan karena tidak adanya kenaikan jam kerja yang dilakukan pihak Industri Kerupuk Jangek Malalo dalam kegiatan produksi setiap harinya.

Tabel 6 Rekapitulasi Selisih Biaya Tenaga Kerja 2018

\begin{tabular}{cc}
\hline Selisih & Jumlah (Rp) \\
\hline $\begin{array}{c}\text { Selisih Biaya Tenaga } \\
\text { Kerja }\end{array}$ & 15.552 .000 \\
\hline $\begin{array}{l}\text { Penyimpangan } \\
\text { Efisiensi BTK }\end{array}$ & 12.672 .000 \\
\hline Total Selisih BTK & 28.224 .000 \\
\hline \multicolumn{2}{l}{ Sumber: Data diolah peneliti, 2019) }
\end{tabular}

Hasil analisis selisih biaya tenaga kerja memperlihatkan bahwa terdapat selisih yang tidak menguntungkan yaitu sebesar Rp15.522.000,00. Hal ini disebabkan karena naiknya tarif upah sesungguhnya sebesar Rp750,00/jam dari tarif upah standar Rp5.500,00/jam menjadi Rp6.250,00/jam. Hal ini dapat terjadi karena naiknya tingkat produksi di Industri Kerupuk Jangek Malalo, sehingga perusahaan harus menaikan tarif upah untuk meningkatkan kinerja karyawan. Kemudian hasil perhitungan analisis selisih penyimpangan biaya tenaga kerja menunjukkan adanya selisih yang tidak menguntungkan yaitu sebesar Rp12.672.000,00 yang disebabkan karena meningkatnya jam kerja sesungguhnya sebanyak 20.736 jam dari jam kerja standar yang ditetapkan ditahun sebelumnya yaitu sebanyak 18.432 jam/tahun. Kenaikan jam kerja sesungguhnya disebabkan 
karena adanya penambahan karyawan sebanyak satu orang dalam kegiatan produksi di Industri Kerupuk Jangek Malalo Kota Lubuklinggau.

\section{Biaya Overhead Pabrik}

Biaya overhead pabrik adalah seluruh biaya yang dikeluarkan dalam kegiatan produksi di luar dari pembelian bahan baku langsung dan biaya tenaga kerja langsung. Biaya overhead pabrik meliputi biaya variabel dan tetap, dimana biaya tetap dalam Industri Kerupuk Jangek Khas Malalo Kota Lubuklinggau ini adalah biaya penyusutan dan biaya variabel merupakan biaya bahan penolong dan listrik.

Tabel 7 Selisih Biaya Overhead Pabrik

\begin{tabular}{ccc}
\hline $\begin{array}{c}\text { Tahun 2016 } \\
(\mathrm{Rp})\end{array}$ & $\begin{array}{c}\text { Tahun 2017 } \\
(\mathrm{Rp})\end{array}$ & $\begin{array}{c}\text { Selisih Biaya } \\
\text { Bahan Baku } \\
(\mathrm{Rp})\end{array}$ \\
\hline 52.743 .600 & 67.599 .600 & 14.856 .000 \\
\hline $\begin{array}{c}\text { Tahun 2017 } \\
(\mathrm{Rp})\end{array}$ & $\begin{array}{c}\text { Tahun 2018 } \\
(\mathrm{Rp})\end{array}$ & $\begin{array}{c}\text { Selisih Biaya } \\
\text { Bahan Baku } \\
(\mathrm{Rp})\end{array}$ \\
\hline 67.599 .600 & 89.847 .600 & 22.248 .000 \\
\hline
\end{tabular}

(Sumber: Data diolah peneliti, 2019)

Tabel 8 Rekapitulasi Selisih Biaya Overhead Pabrik 2017

\begin{tabular}{cc}
\hline Selisih & Jumlah $(\mathrm{Rp})$ \\
\hline $\begin{array}{c}\text { Selisih Terkendali } \\
\text { dan Selisih BOP }\end{array}$ & 14.856 .000 \\
\hline Total Selisih BOP & 14.856 .000 \\
\hline (Sumber: Data diolah peneliti, 2019)
\end{tabular}

Hasil analisis selisih biaya overhead pabrik menunjukkan bahwa biaya overhead pabrik sesungguhnya lebih besar dibandingkan anggaran fleksibel biaya overhead pabrik pada kapasitas standar. Hal ini bermakna bahwa biaya overhead pabrik mengalami selisih tidak menguntungkan sebesar Rp14.856.000,00 dalam kegiatan produksi. Kemudian dari analisis selisih volume dapat diketahui bahwa terjadi selisih tidak menguntungkan bagi Industri Kerupuk Jangek Khas Malalo sebesar Rp14.856.000,00. Hal ini disebabkan karena tarif total BOP sesungguhnya lebih besar dari tarif total BOP standar. Tarif BOP sesungguhnya yaitu sebesar $\mathrm{Rp} 7.884,24,00 / \mathrm{Kg}$.

Tabel 9 Rekapitulasi Selisih Biaya Overhead Pabrik 2018

\begin{tabular}{cc}
\hline Selisih & Jumlah (Rp) \\
\hline $\begin{array}{c}\text { Selisih Terkendali } \\
\text { dan Selisih Volume }\end{array}$ & 22.248 .000 \\
\hline Total Selisih BOP & 22.248 .000 \\
\hline (Sumber: Data diolah peneliti, 2019)
\end{tabular}

Hasil analisis selisih biaya overhead pabrik menunjukkan bahwa biaya overhead pabrik sesungguhnya lebih besar dibandingkan anggaran fleksibel biaya overhead pabrik pada kapasitas standar yaitu dapat dinyatakan bahwa terjadinya selisih tidak menguntungkan sebesar sebesar Rp22.248.000,00 dalam kegiatan produksi di Industri Kerupuk Jangek Khas Malalo Kota Lubuklinggau. Kemudian dari analisis selisih volume dapat diketahui bahwa terjadi selisih tidak menguntungkan bagi Industri Kerupuk Jangek Khas Malalo yaitu sebesar Rp22.248.000,00. Hal ini disebabkan oleh tarif total BOP sesungguhnya lebih besar dari tarif total BOP standar. Tarif BOP sesungguhnya yaitu sebesar Rp8.801,68,00/Kg.

Hasil penelitian menunjukkan bahwa Industri Kerupuk Jangek Khas Malalo Kota Lubuklinggau mengalami selisih yang tidak menguntungkan (unfavorable) dalam pembelian bahan baku produksinya. Kemudian pengendalian biaya tenaga kerja belum berjalan secara efektif karena industri ini menaikkan tarif upah dan ada penambahan karyawan sebanyak 1 orang. Selain itu pengendalian biaya 
overhead pabrik juga belum berjalan efektif karena industri ini tidak melakukan perhitungan sesuai dengan perhitungan yang sesungguhnya. Hal yang sama juga terjadi pada PT. Conbloc Indonesia Surya Cabang Sulawesi Utara, dimana dalam menetapkan biaya standar perusahaan hanya menggunakan anggaran yang didasari pengalaman dan informasiinformasi yang tersedia yang berhubungan dengan kemungkinan harga dimasa yang akan datang, sehingga perusahaan mengasumsikan bahwa mereka dapat menentukan taksiran harga yang akan berlaku pada tahun mendatang untuk membagi biaya bahan baku, biaya tenaga langsung, biaya overhead pabrik. Namun ternyata hal tersebut membuat perusahaan harus mengeluarkan biaya melebihi biaya bahan baku standarnya. Selain itu biaya overhead pabrik juga sempat mengalami ketidakefisienan (Salmon \& Runtu, 2016).

Permasalahan-permasalahan ini dapat muncul karena perusahaan tidak menerapkan biaya standar untuk mengendalikan biaya produksinya. Hal ini dibuktikan oleh Pratiwi (2013) yang menemukan bahwa apabila perusahaan menerapkan biaya standar untuk mengendalikan biaya produksinya, maka perusahaan dapat mengefisiensikan biaya produksinya seoptimal mungkin.

Pengendalian dibutuhkan dalam setiap pekerjaan untuk mengevaluasi setiap kegiatan yang telah dilaksanakan agar tidak menyimpang dan sesuai dengan rencana yang telah ditetapkan sebelumnya. Secara umum pengendalian biaya produksi dilakukan dengan cara membandingkan antara biaya yang dikorbankan dengan biaya yang ditentukan sebelumnya, apakah biaya tersebut masih dalam batas-batas kewajaran atau tidak. Penyimpangan yang terjadi harus diketahui dengan cepat dan dianalisa agar dapat diambil tindakan seefektif mungkin, penentuan biaya standar dan analisis biaya dari fungsi akuntansi biaya berperan untuk mengendalikan biaya (Nasa, 2012).

Menurut Salman (2013) dalam merancang biaya standar, perusahaan dapat menggunakan beberapa jenis standar yaitu: a) standar ideal (ideal standard) merupakan efisiensi maksimum dan hanya dapat dicapai apabila semua proses berjalan dengan lancar; b) standar yang saat ini dapat tercapai (currently attainable standards) merupakan standar yang dapat dicapai apabila kondisi operasi berlangsung dengan efisien.

\section{PENUTUP}

\section{Kesimpulan}

Industri Kerupuk Jangek Khas Malalo Kota Lubuklinggau dalam produksinya selama tahun 2016-2018 selalu mengalami peningkatan produksi. Namun pengendalian biaya bahan baku pada industri ini belum berjalan secara efektif karena dalam pembelian bahan baku terjadi kenaikan harga pada tahun 2017 dan tahun 2018. Kenaikan biaya bahan baku tersebut dipengaruhi naiknya harga kikil basah sehingga pemasok menaikkan harga jual kulit sapi kering. Industri Kerupuk Jangek Khas Malalo Kota Lubuklinggau ini mengalami selisih yang tidak menguntungkan (unfavorable) dalam pembelian bahan baku.

Industri Kerupuk Jangek Khas

Malalo Kota Lubuklinggau dalam menentukan biaya tenaga kerja yang dikeluarkan untuk membayar karyawan pada tahun 2016 dan 2017 belum berjalan efektif karena harus menaikkan tarif upah dan ada penambahan karyawan sebanyak satu orang sehingga Industri Kerupuk Jangek Khas Malalo Kota Lubuklinggau ini mengalami 
selisih yang tidak menguntungkan (unfavorable).

Biaya overhead pabrik yang dikeluarkan oleh industri ini dalam kegiatan produksi selama tahun 20162018 selalu mengalami peningkatan. Hal ini dipengaruhi oleh pembelian bahan penolong yang selalu mengalami kenaikan harga dan jumlah bahan penolong yang digunakan selalu meningkat. Biaya penyusutan peralatan di Industri Kerupuk Jangek Khas Malalo ini tidak diperhitungkan berdasarkan metode penyusutan peralatan melainkan hanya mencatat biaya yang dikeluarkan pada saat pembelian peralatan. Dengan demikian pengendalian biaya overhead pabrik belum berjalan efektif karena tidak melakukan perhitungan sesuai dengan perhitungan yang sesungguhnya sehingga Industri Kerupuk Jangek Khas Malalo Kota Lubuklinggau ini mengalami selisih yang tidak menguntungkan (unfavorable).

\section{Saran}

Industri Kerupuk Jangek Khas

Malalo Kota Lubuklinggau perlu menerapkan biaya standar agar dapat mengendalikan biaya produksi karena kegiata produksi yang dilakukan Industri sudah berjalan dengan baik namun kurangnya pengendalian biaya produksi yang dilakukan dalam kegiatan produksi.

Biaya Tenaga Kerja yang dikeluarkan untuk menggaji karyawan harus lebih diperhitungkan. Sebaiknya dalam kegiatan produksi Industri Kerupuk Jangek Khas Malalo menambahkan jam kerja dalam kegiatan produksi menjadi 9 jam dan menaikan gaji per produksi dengan 8 orang karyawan akan lebih efisien dan efektif dalam kegiatan produksi dan mengurangi biaya yang dikeluarkan untuk membayar gaji karyawan.

Biaya overhead pabrik di Industri Kerupuk Jangek Khas Malalo harus diperhitungkan lebih rinci lagi mengenai banyak bahan penolong yang dibutuhkan dan biaya yang akan dikeluarkan setiap kali produksi.

\section{DAFTAR PUSTAKA}

Kurniawan, D. (2012). Penerapan Sistem Akuntansi Biaya untuk Meningkatkan Tingkat Akurasi Biaya Produksi (Studi Praktik Kerja pada PT. Hamparan Plastindo Raya). Jurnal Ilmiah Mahasiswa Akuntansi, 1(1), 1620

Mulyadi, M. (2014). Akuntansi Biaya, Edisi Ke-5. Yogyakarta: Universitas Gajah Mada

Nasa, L. A. (2012). Penerapan Biaya Standar terhadap Pengendalian Biaya Produksi (Studi Kasus pada CV. Sejahtera Bandung). Jurnal Ilmiah Akuntansi, 7(3), 120

Pratiwi, J. (2013). Penerapan Biaya Standar dalam Pengendalian Biaya Produksi pada PT. Pertani (Persero) Cabang Sulawesi Utara. Jurnal EMBA, 1(4), 16171626

Salmon, D., \& Runtu, T. (2016). Penerapan Biaya Standar Sebagai Alat Pengendalian Biaya Produksi pada PT. Conbloc Indonesia Surya Cabang Sulawesi Utara. Jurnal EMBA, 4(1), 880-888

Undang-Undang Nomor 20. (2008). Usaha Mikro, Kecil dan Menengah. https://peraturan.bpk.go.id/Hom e/Details/39653/uu-no-20-tahun$\underline{2008}$ 